\title{
Correlation of Albumin Serum Levels as Inflammation Marker with Red Blood Cell Distribution Width Value in Regular Hemodialysis Patients at H. Adam Malik General Hospital Medan
}

\author{
Soraya Mourina Hutasuhut ${ }^{1}$, Alwi Thamrin Nasution², \\ M. Feldy Gazaly Nasution ${ }^{2}$
}

\author{
${ }^{1}$ Department of Internal Medicine, Faculty of Medicine, Universitas Sumatera Utara, Medan, Indonesia \\ ${ }^{2}$ Division of Nephrology and Hypertension, Department of Internal Medicine, Faculty of Medicine, Universitas \\ Sumatera Utara, Medan, Indonesia \\ Corresponding Author: Soraya Mourina Hutasuhut
}

\begin{abstract}
Background: One of the modalities of renal replacement therapy in chronic kidney disease (CKD) is hemodialysis (HD). The role of inflammation in HD patients by uremic toxins and dialysis can be assessed by the marker of serum albumin. This inflammation also causes dysregulation of the hormone erythropoietin which results in increased variability or heterogeneity of red blood cell distribution width (RDW). Previous studies have revealed an association between RDW and albumin levels in regular HD patients which leads to increased patient morbidity and mortality. This study aims to determine the relationship between albumin serum levels and RDW as a marker of inflammation in regular HD patients.
\end{abstract}

Method: This was a cross sectional study design, conducted in June to August 2020 at the HD unit of Haji Adam Malik General Hospital in Medan. Twenty subjects were included. Data were analyzed using Pearson correlation test and T-test to find the correlation between albumin serum levels and RDW, and other variables.

Results: Of the 20 subjects taken based on consecutive sampling, the majority was male, 13 people $(65 \%)$, mean age was $50.30 \pm 12.57$ years with the most comorbid type 2 diabetes mellitus for 14 people $(70 \%)$. The mean serum albumin level was $3.2 \pm 0.65 \mathrm{mg} / \mathrm{dl}$. The mean RDW value was $15.93 \pm 1.87 \%$. This study showed that there was a significant relationship between serum albumin levels and RDW values $(\mathrm{r}=-0.687 ; \mathrm{p}=0.001)$. RDW values were also significantly associated with hemoglobin levels $(\mathrm{r}=0.497 ; \mathrm{p}=0.026)$ and creatinine $(\mathrm{r}=0.519$; $\mathrm{p}=0.019$ ).

Conclusion: Albumin, hemoglobin, and creatinine levels were significantly associated with RDW values in regular HD patients.

Keywords: inflammation, albumin, regular hemodialysis, RDW

\section{INTRODUCTION}

The prevalence of chronic kidney disease (CKD) and its risk factors is increasing worldwide, and is the biggest challenge for health systems, especially in low and middle-income countries. ${ }^{[1]}$ CKD is a global health burden with high costs and a risk factor for cardiovascular disease. ${ }^{[2]}$ Based on the Indonesian Renal Registry, in 2017 , it was reported that $0.03 \%$ of the Indonesian population underwent hemodialysis. ${ }^{[3}$

Red cell distribution width (RDW) may be increased because of a deficit in erythropoiesis or an increase in red cell destruction. RDW increased significantly in patients with CKD grades 1 to 5 where the higher the RDW, the higher the staging (Lu et al, 2017). ${ }^{[4]}$ In recent years, RDW is the most recent predictor of mortality for various populations. Although the 
mechanism of RDW associated with mortality remains unclear, it is thought to be a marker of inflammation and malnutrition.

Serum albumin is important as a parameter in assessing nutritional status in acute or chronic disease. ${ }^{[5]}$ Renal replacement therapy is an inflammatory state in which albumin synthesis also decreases while albumin destruction is increased. In previous studies it was also stated that morbidity and mortality were inversely correlated with serum albumin values, especially in patients with end-stage CKD. Albumin creatinine ratio (ACR) is also significant and associated with decreased kidney function. ${ }^{[6]}$

Several mechanisms are thought to link RDW with hypo-albumin. First, the RDW acts as a general marker of the severity of various comorbidities. Second, previous studies have shown that inflammation, oxidative stress, and malnutrition may mediate the association between RDW and poor outcome. Where in the state of inflammation and oxidative stress are closely related to low albumin, moreover malnutrition is one of the important characteristics of CKD. In addition, RDW is also associated with endothelial dysfunction associated with various diseases that arise with hypoalbumin. ${ }^{[7]}$

Due to the increasing number of patients undergoing hemodialysis and so far the RDW value has only been used as a marker to explain the state of anemia, several previous studies were conducted abroad and linked it to mortality, while research studies in Indonesia did not have data on the relationship between albumin inflammatory biomarkers and RDW values in patients undergoing hemodialysis.

\section{MATERIAL AND METHODS}

This was a cross sectional study design which assessed the relationship between albumin levels as a marker of inflammation and the RDW value in patients undergoing regular hemodialysis. The study was conducted in August 2020 in the Hemodialysis Unit of Haji Adam Malik General Hospital in Medan. Subjects were patients undergoing regular hemodialysis at Hemodialysis Unit of Haji Adam Malik General Hospital Medan in 2020. Inclusion criteria were male and female patients aged $\geq 18$ years, undergoing regular hemodialysis $>3$ months, and willing to be included in the study. Exclusion criteria were patients with a history of liver disease, and patients with infection or malignancy.

Every patient undergoing regular hemodialysis at Haji Adam Malik General Hospital Medan who met the inclusion criteria and did not meet the exclusion criteria was a research subject and the patient then filled out an informed consent letter. The research subjects were selected consecutively. Patients were examined for vital signs, anthropometry and venous blood collection for routine blood and albumin examinations, blood samples were taken shortly before the hemodialysis session.

\section{Statistical Methods}

Univariate and bivariate analyzes were performed. Univariate analysis was performed to obtain the distribution of sample characteristics. Bivariate analysis was conducted to determine the relationship between the independent and dependent variables. The normalization test was carried out by the Shapiro-Wilk test. The statistical test used was the Pearson correlation test with the alternative Spearman test for the abnormal data distribution. Data was analyzed using computer program SPSS version 23 (Statistical Product and Service Solution) and $95 \%$ confidence interval. Significant value if $\mathrm{p}<0.05$.

\section{RESULTS}

Twenty subjects met the inclusion criteria, 13 people were male $(65.0 \%)$ and 7 were women $(35.0 \%)$. The mean age was $50.3 \pm 12.57$ years. The mean eGFR and albumin were $5.95 \pm 3.11$ and $3.2 \pm 0.65$, respectively. Meanwhile, the average RDW value is $15.93 \pm 1.87$. 
Table 1. Characteristics of the research sample

\begin{tabular}{|l|l|}
\hline Characteristics & $\mathbf{N}=\mathbf{2 0}$ \\
\hline Gender, n (\%) & $13(65 \%)$ \\
Male & $7(35 \%)$ \\
\hline Female & $50.3 \pm 12.57$ \\
\hline Age (years), mean \pm SD & $24.45 \pm 20.98$ \\
\hline $\begin{array}{l}\text { Length of time a patient underwent HD } \\
\text { (months), mean } \pm \text { SD }\end{array}$ & $4(20 \%)$ \\
\hline Hypertension, $\mathrm{n}(\%)$ & $14(70 \%)$ \\
\hline Diabetes mellitus, $\mathrm{n}(\%)$ & $2(10 \%)$ \\
\hline Glomerulonephritis, $(\%)$ & $9.12 \pm 0.57$ \\
\hline Haemoglobin $(\mathrm{g} / \mathrm{dl})$ & $7912 \pm 3108$ \\
\hline Leucocyte & $21.25 \pm 5.1$ \\
\hline Lymphocyte & $4.45 \pm 3.41$ \\
\hline Eosinophil & $64.9 \pm 8.08$ \\
\hline Neutrophil & $147.1 \pm 33.62$ \\
\hline Urea $(\mathrm{mg} / \mathrm{dl})$ & $10.1 \pm 4.02$ \\
\hline Creatinine $(\mathrm{mg} / \mathrm{dl})$ & $5.95 \pm 3.11$ \\
\hline eGFR (ml/min) & $3,2 \pm 0.65$ \\
\hline Albumin $(\mathrm{mg} / \mathrm{l})$ & $15.93 \pm 1.87$ \\
\hline RDW & \\
\hline
\end{tabular}

Based on statistical tests, there was no significant relationship between the etiology of CKD, both DM and hypertension, on albumin and RDW levels in both groups of patients undergoing hemodialysis and those not undergoing hemodialysis ( $\mathrm{p}>0.05)$.

Table 2. Etiology relationship of CKD with albumin and RDW

\begin{tabular}{|l|l|l|l|l|}
\hline Variable & $\begin{array}{l}\text { DM } \\
(\text { mean } \pm \text { SD) }\end{array}$ & $\boldsymbol{p}$. & $\begin{array}{l}\text { Hypertension } \\
(\text { mean } \pm \text { SD) }\end{array}$ & $\boldsymbol{p}$. \\
\hline RDW & $16.37 \pm 1.95$ & 0.210 & $15.05 \pm 1.17$ & 0.207 \\
\hline Albumin & $3.17 \pm 2.83$ & 0.406 & $3.17 \pm 6.98$ & 0.324 \\
\hline
\end{tabular}

Correlation between length of time a patient underwent HD with albumin levels and RDW in regular hemodialysis patients was $r=0.244$ and 0.058 with $p=0.301=$ 0.807 . These results indicate that length of time a patient underwent HD was not related to albumin levels and RDW in regular hemodialysis patients.

Table 3. Correlation of length of time a patient underwent HD with albumin and RDW

\begin{tabular}{|l|l|l|}
\hline Variable & $\begin{array}{l}\text { Length of time a patient underwent HD } \\
\text { (months) } \\
\text { r }\end{array}$ & $\boldsymbol{p}$. \\
\hline Albumin & 0.244 & 0.301 \\
\hline RDW & 0.058 & 0.807 \\
\hline
\end{tabular}

A significant correlation was found between albumin levels and RDW values in regular hemodialysis patients $(r=-0.687$; $\mathrm{p}=0.001$, the level of relationship between RDW and albumin was in the strong correlation category (between the range 0.61-0.80), because the Pearson Correlation value was negative (-), the direction of the relationship between RDW and albumin was negative or inversely proportional, where the higher the value of the RDW variable, the lower the value of the albumin variable and the lower the value of the RDW variable, the higher the value of the albumin variable.

There was a significant correlation between RDW values and serum creatinine and hemoglobin levels in regular hemodialysis patients, each with statistical results $(\mathrm{r}=0.497 ; \mathrm{p}=0.02) ;(\mathrm{r}=0.519 ; \mathrm{p}=$ $0.01)$, respectively]. Based on statistical tests, there was no correlation between urea and eGFR parameters with RDW values in regular hemodialysis patients ( $\mathrm{p}>0.05$ ). These results indicate the strong relationship between albumin levels and RDW values in regular hemodialysis patients.

Table 4 Correlation of RDW with other parameters in regular HD patients

\begin{tabular}{|l|l|l|}
\hline \multirow{2}{*}{ Variable } & RDW \\
\cline { 2 - 3 } & r & p. \\
\hline Hemoglobin & 0.497 & $0.026^{*}$ \\
\hline Urea & 0.124 & 0.603 \\
\hline Creatinine & 0.519 & $0.019^{*}$ \\
\hline eGFR & 0.379 & 0.100 \\
\hline Albumin & 0.687 & 0.001 \\
Basophil & 0.345 & 0.137 \\
Neutrophil & 0.464 & $0.039^{*}$ \\
Eosinophil & 0.317 & 0.174 \\
Lymphocyte & 0.379 & 0,099 \\
\hline
\end{tabular}

Neutrophil variable and RDW had a significant correlation $(p=0.039)$ with correlation coefficient value $r=0.464$, meaning that the level of relationship between neutrophils and RDW was sufficient (between the range 0.26-0.50). The correlation coefficient value was positive (+), so the direction of the relationship between albumin and RDW was positive or directly proportional, where the higher the value of the neutrophil, the higher the value of the RDW and the lower the value of the neutrophil variable, the lower the value of the RDW variable. There was no relationship between the parameters of basophil, eosinophil, and lymphocyte with RDW in patients undergoing regular hemodialysis.

\section{DISCUSSION}

Of the 20 research subjects, the majority of the research subjects were 
male, 13 people $(65 \%)$ with the mean age of $50 \pm 12.57$. This study is in line with the 2017 IRR report where the highest proportion of patients undergoing HD is in the 45-64 year age range. The age factor, in this case aging, affects the structure and regulatory function of the kidney, which causes the progressive worsening of CKD. ${ }^{[3]}$

The most comorbid disease in this study was diabetes mellitus followed by hypertension. This is in line with data from USRDS 2015 where diabetes mellitus is the main cause of CKD in the United States. However, this data is inversely proportional to data obtained from Indonesian Renal Registry in 2017, the most common cause of CKD in Indonesia is hypertension (44\%) followed by diabetes mellitus (22\%) and other diseases. ${ }^{[3,8]}$

In this study, it was found that there was no relationship between the etiology of CKD, both DM and hypertension, with albumin and RDW levels. This is in line with the results of research by Hseihs et al, who also concluded that there was no relationship between albumin levels and diabetes and hypertension status in their study (Hseihs, 2016). ${ }^{[9]}$ The most common etiology of CKD based on literature research is diabetes mellitus and hypertension, but it can also be caused by kidney infection, gouty nephropathy, kidney cysts and obstructive nephropathy. This proves that whatever the etiology of CKD in a patient, it has no direct effect on inflammation that occurs in the course of the disease in regular hemodialysis patients, so it also has no effect on changes in RDW values in regular hemodialysis patients. According to Ackhurin in his writings on inflammation in CKD, inflammation that occurs in the course of CKD is caused by decreased cytokine elimination, repeated infections, oxidative stress, intestinal dysbiosis, periodontal disease, metabolic acidosis, vitamin D deficiency and dialysisrelated factors directly caused by the underlying disease. ${ }^{[10]}$

Albumin and RDW levels in this study were not related to the length of time a patient underwent HD. This data is not in line with $\mathrm{Li}, 2014$ which states that patients undergoing hemodialysis for more than 1 year have lower albumin levels of $3.68 \mathrm{~g}$ compared to patients undergoing hemodialysis under one year with a mean albumin value of $4 \mathrm{~g} / \mathrm{dl}(\mathrm{p}=0.004){ }^{[11]}$

The length of time a patient underwent $\mathrm{HD}$ is not directly related to inflammation in regular hemodialysis patients and subsequently to changes in inflammation-related RDW levels caused by uremia toxin and exposure to hemodialysis itself. Through the hemodialysis process, the uremic toxin will be removed through the machine, marked by decreased urea levels after HD, so that within 24 hours after HD the uremia level is relatively close to the normal range. After 24 hours until the next HD session, the uremic toxin then collects again, which of course increases inflammation in HD patients, and so the process continues.

CKD is characterized by irreversible changes in kidney function, which then causes multi-organ dysfunction in the development of the clinical syndrome of uremia. Inflammation in regular hemodialysis patients is associated with RDW values caused by impaired production of the hormone erythropoietin. Uremic patients show complex renal dysfunction characterized by a decrease in erythropoietin levels resulting in an increase in the variation of red cell distribution, namely the RDW value. Hemodialysis is associated with changes in the RDW value, where an increase in the RDW value is a consistent parameter change found in these conditions. ${ }^{[12,13]}$

In this study, an increase in the RDW value was found. In line with the Tekce study, RDW levels were found to be elevated in regular hemodialysis patients for $68.9 \% .^{[13]}$ Other factors that have been previously disclosed affect changes in RDW levels in hemodialysis patients in addition to uremia toxins and the hemodialysis process. itself, namely albumin levels, which reflect the inflammatory status of the patient. 
Inflammation itself is influenced by many factors that will later contribute to the progression of this disease.

This study found a strong negative correlation between albumin levels and RDW values. This is in line with the Tekce study which showed a strong negative correlation between RDW values and albumin levels in hemodialysis patients $(\mathrm{r}=$ 0.815; $\mathrm{p}=0.014) .{ }^{[13]}$ Similar research was also revealed by Lippi, where a negative correlation was found between albumin levels and RDW values. ${ }^{[14]}$

This study limitation was the crosssectional design which allows the data and the results of data analysis not to fully describe variations in albumin levels and RDW values of regular hemodialysis patients, while in previous studies conducted abroad (Turkey, Japan, and Budapest) using a prospective cohort study design. It is necessary to conduct further research on RDW levels carried out in multi centers so that the data obtained can represent regular hemodialysis patients in Indonesia. The next researcher can continue the research by observing clinical outcomes such as mortality and survival of regular hemodialysis patients to see the effect of RDW values on clinical outcomes of regular hemodialysis patients.

\section{CONCLUSIONS}

There was a significant relationship between albumin levels and RDW values in regular hemodialysis patients, and no relationship between the etiology of CKD patients and RDW values in regular hemodialysis patients. There was no relationship between the length of time a patient underwent hemodialysis and RDW values in regular hemodialysis patients and there was a significant relationship between hemoglobin, creatinine, and neutrophil with RDW value in regular hemodialysis patients.

\section{ACKNOWLEDGEMENTS}

This research was supported by the Faculty of Medicine Universitas Sumatera
Utara. The authors thank colleagues from the Division of Nephrology and Hypertension, Department of Internal Medicine for providing insight, assistance and expertise that had greatly helped authors throughout this research.

\section{Conflict of Interest: None}

\section{Source of Funding: None}

\section{Ethical Approval: Approved}

\section{REFERENCES}

1. Yang, C., Harris, D. C., Luyck, V. A., Masaomi, N., Hou, F. F., Garcia, G. G., et al. 2020. Global Case Study for Chronic Kidney Disease/ End-stage Kidney Disease Care. Kidney International Supplements.10, e24-e48.

2. Hill, N.R., Fatoba, S.T., Oke, J.L., Hirst, J.A., O'Callaghan, C.A., Lasserson, D.S., et al. 2016. Global prevalence of chronic kidney disease-a systematic review and meta-analysis. PloS one, 11(7):e0158765.

3. 11th Report of Indonesian Renal Registry. IRR. 2018. Available from: https://www.indonesianrenalregistry.org/dat $\mathrm{a} / \mathrm{IRR} / 2018$.

4. Lu, Y., Fan, P., Lee, C., Wu., V. C., Tian, Y., Yang, C., et al. 2017. Red cell distribution width associated with adverse cardiovascular outcomes in patients with chronic kidney disease. BMC Nephrol. 18(1):361.

5. Akirov, Iraqi, H.M., Atamna, A., Shimon, I. 2017. Low Albumin Levels Are Associated with Mortality Risk in Hospitalized Patients. Am J Med, 130(12).

6. Lang, J., Katz, R. Joachim, H., Gutierrez, O. M., Peralta, C. A., Parikh, C. R., et al 2017. Association of serum albumin levels with kidney function decline and incident chronic kidney disease in elders. Nephrol Dial Transplan. 33(6):986-92.

7. Hyun, Y. Y., Kim H. and Lee, K. 2017. Red cell distribution width predicts incident dipstick albuminuria in Korean adults without chronic kidney disease. Kidney res Clin Path. 36(3): 232-39.

8. System USRD. Annual Data Report: Epidemiology of Kidney Disease in The 
Soraya Mourina Hutasuhut et.al. Correlation of albumin serum levels as inflammation marker with red blood cell distribution width value in regular hemodialysis patients at H. Adam Malik General Hospital Medan.

United States. 2015. Available from: https://pubmed.ncbi.nlm.nih.gov/26925525/

9. Hsieh, Y. P., Chang, C., Kor, C., Yang, Y., Wen, Y., Chiu, P. 2016. The Predictive Role of Red Cell Distribution Width in Mortality among Chronic Kidney Disease Patients. Plos One. 11(12): e0162025

10. Ackhurin, Frederick, K. 2015. Update on Inflamation in Chronic Kidney Disease. Blood Purif. 39(1-3):84-92

11. Li, Z., Chen, L., Yuan, H., Zhao, T. and Kuang, Z. 2014. Relationship Between Red Cell Distribution Width and Early-stage Renal Function Damage in Patients with Essential Hypertension. $J$ Hypertens. 32(12):2450-5.

12. Guclu, A., Tokmak, T.T., Kaymaz, H., Turkmen, K., Senol, H., Ozhan, N., et al. 2016. The Relationship of Red-Cell Distribution Width and Carotid Intima Media in Chronic Kidney Disease. Nefroloji Bilim Dalı, Kırsehir, Turkey.
13. Tekce H, Kin Tekce B, Aktas G, Tanrisev, M., and Sit, M. 2014. The evaluation of red cell distribution width in chronic hemodialisis patients. Int $\mathbf{J}$ Nephrol. 754370 .

14. G. Lippi, F. Pavesi, M. Bardi, S, Pipitone. Lack of Harmonization of Red Blood Cell Distribution Width (RDW): evaluation of Four Hematological Analyzers. Clin Biochem, 2014; 47(12):1100-1103.

How to cite this article: Hutasuhut SM, Nasution AT, M. Feldy Gazaly Nasution. Correlation of albumin serum levels as inflammation marker with red blood cell distribution width value in regular hemodialysis patients at H. Adam Malik General Hospital Medan. International Journal of Research and Review. 2021; 8(7): 369-374. DOI: https://doi. org/10.52403/ijrr.20210752 